\title{
KAJIAN BIBLIKA TENTANG PENGHINAAN TERHADAP \\ YESUS BERDASARKAN MARKUS 15:16-20 DAN \\ IMPLIKASINYA BAGI KEHIDUPAN \\ ORANG PERCAYA MASA KINI
}

Nata Mandala Apuy, Peniel C. D. Maiaweng

\begin{abstract}
Abstrak
Tujuan penulisan skripsi ini adalah menjelaskan secara Alkitabiah tentang penghinaan yang dilakukan terhadap Yesus dan membuat implikasi Teologis dan implikasi praktis bagi kehidupan orang percaya masa kini berdasarkan Markus 15:16-20. Adapun metode yang digunakan oleh penulis adalah penelitian kualitatif yaitu menggunakan prinsipprinsip hermeneutik, eksegesis dan penafsiran, dengan mengunakan analisis konteks, penjelasan nas, analisis teks dengan memakai analisa leksikal atau mencari makna dari setiap kata-kata penting dalam nas. Dari hasil penelitian ini maka penulis menarik beberapa kesimpulan. Pertama, sesuai dengan latar belakang masalah dari penulisan skripsi ini, yaitu tentang penghinaan yang dilakukan terhadap Yesus, maka penulis menyimpulkan bahwa jubah ungu yang dikenakan pada Yesus merupakan kain ungu biasa, yang kemungkinan hanya merupakan kain berwarna merah tua yang sudah tidak terpakai, kemungkinan pakaian bekas serdadu-serdadu tersebut dan bukan merupakan jubah kebesaran Raja yang berwarna ungu. Dan maksud dari perlakukan ini adalah untuk mentertawakan Yesus dan menghina Yesus yang disebut sebagai Raja orang Yahudi. Kedua, dari penghinaan yang dilakukan terhadap Yesus, maka Yesus sudah menggenapi nubuatan tentang Diri-Nya (Yesaya 53:1-12) penghinaan yang dilakukan terhadap Yesus merupakan bagian dari penggenapan nubuat tentang Diri-Nya. Ketiga, Tuhan Yesus telah memberikan suatu teladan hidup bagi setiap orang percaya, dengan taat sampai mati, dan setiap orang percaya harus menghargai apa yang telah Tuhan Yesus lakukan, yaitu dengan hidup taat sepenuhnya kepada Allah.
\end{abstract}

Kata Kunci: Penghinaan, Kain Ungu, Nubuat, Taat, Teladan.

\section{Pendahuluan}

\section{Latar Belakang Masalah}

Penyaliban merupakan klimaks dari cerita Injil, di mana masing-masing penulis Injil menuliskan cerita tentang penyaliban dengan gaya penulisannya yang berbedabeda. Berbeda dengan Injil Yohanes, ketiga Injil lainnya, yaitu Injil Markus, Matius dan Lukas yang disebut sebagai Injil sinoptik menulis dengan cara pandang yang sama, namun dalam kesamaan ketiga Injil sinoptik, nampak bahwa Markus sangat unik dari tulisan Injil lainnya, di mana Markus nampak terlihat menulis dengan begitu ringkas 
dan terlihat tidak bertele-tele dibanding dengan Injil lain. Menurut beberapa ahli, keunikan Markus merupakan suatu hal yang menunjukkan identitasnya sebagai Injil yang tertua. Dalam tulisannya, Suharyo menerangkan memang masih dapat dikatakan bahwa Injil Markus adalah Injil yang pertama ditulis dan kemudian Matius dan Lukas menggunakannya. ${ }^{1}$

Dalam cerita Injil, salah satu topik terbesar dan yang merupakan inti dari cerita Injil ialah tentang penderitaan Tuhan Yesus, di mana nubuatan tentang Mesias yang menderita digenapi. Tuhan Yesus mengalami semua yang dinubuatkan tentang diri-Nya, Ia menderita, sebagai orang yang dihina, penuh kesengsaraan, dianiaya dan terhitung di antara pemberontak-pemberontak, karena Allah berkehendak meremukkanya, karena dosa umat-Nya (Yesaya 53:1-12). Dalam skenario penderitaan-Nya, Ia harus dihukum dengan hukuman salib, karena dengan hukuman salib, nubuatan tersebut tergambarkan, sebab ia terhitung di antara orang-orang pemberontak. Tentang hukuman salib, Aldorio Flavius menerangkan "Salib pada masa itu adalah hukuman orang Romawi yang mengandung pesan takut dan malu yang begitu kuat, mereka yang disalibkan dihina.,"2 John Stott juga menjelaskan sang tahanan pertama-tama akan dipermalukan di hadapan umum dengan ditelanjangi; ia lalu dibaringkan terlentang di tanah, sementara kedua tangannya diikat ke tiang vertikal. ${ }^{3}$ Seperti itulah kemungkinan penderitaan yang dialami oleh Tuhan Yesus.

Dalam penderitaan-Nya, Selain penderitaan fisik, Tuhan Yesus juga menerima penghinaan. Selain dari orang-orang yang mendakwa-Nya, para serdadu, sebelum membawa Tuhan Yesus ke Golgota, juga menghina Tuhan Yesus dengan begitu luar biasa. Penghinaan tersebut adalah Ia diperlakukan semena-mena oleh serdadu-serdadu yang menyiksa-Nya, Yesus dikenakan jubah ungu, dipakaikan mahkota duri, diludahi dan Yesus diolok-olok. Semua atribut yang dikenakan pada Yesus merupakan gambaran atribut yang dikenakan oleh seorang Raja, dan serdadu-serdadu tersebut melakukan semua itu bertujuan untuk menghina-Nya. Bentuk penghinaan yang dilakukan terhadap Yesus merupakan perlakuan yang sangat keji, oleh karena penghinaan itu merupakan ejekan yang meniru layaknya bagaimana seorang Raja memakai atribut kerajaan, dipermalukan dan dijadikan bahan lelucoan. Mengenai penghinaan yang dilakukan terhadap Tuhan Yesus, yaitu ketika Tuhan Yesus dikenakan jubah ungu, penghinaan ini merupakan anggapan bahwa Yesus adalah raja orang Yahudi, sehingga ia diberikan jubah ungu.

Tentang jubah ungu yang dikenakan pada Yesus, beberapa ahli tafsir telah memberikan keterangan mengenai jubah ungu tersebut. Menurut Dr. Robert Bratcher jubah ungu ini adalah istilah untuk jubah para tentara Romawi. Sebagian bahasa mungkin tidak mempunyai banyak istilah untuk menyebutkan warna-warna yang ada jadi jubah ungu ini perlu diterjemahkan dalam istilah warna yang paling mirip dalam bahasa mereka, misalnya pakaian biru tua atau pakaian raja berwarna merah tua seperti darah. ${ }^{4}$ Ketika Yesus diolok sebagai Raja orang Yahudi, maka selayaknyalah seorang raja mengenakan jubah kebesarannya. Jubah ungu menjadi suatu warna yang memiliki makna keagungan, kebesaran dan kehormatan, oleh karena jubah ungu merupakan jubah yang dipakai seorang Raja.

\footnotetext{
${ }^{1}$ Suharyo, Pengantar Injil Sinoptik (Yogyakarta: Kanisius, 1988), 36.

${ }^{2}$ Aldorio Flavius, "Makna Tujuh Ungkapan Yesus Disalib Bagi Orang Percaya," Jurnal Jaffray Vol. 13, no. 2 (Oktober, 2015): 187.

${ }^{3}$ John Stott, Salib Kristus (Surabaya: Momentum, 2015), 59.

${ }^{4}$ Robert Bratcher dan Eugene A. Nida, Pedoman Penafsiran Alkitab Injil Markus (Jakarta: Lembaga Alkitab Indonesia, 2014), 526.
} 
Timbul suatu pertanyaan dari hal tersebut, yaitu apakah jubah yang dikenakan pada Yesus merupakan jubah ungu yang biasa dikenakan oleh Raja atau kaisar, atau apakah itu memiliki tafsiran lain. Dalam hal ini, Leon Morris mengatakan, "Karena petugas militer memakai jubah seperti ini, mereka tidak terlalu sulit memperolehnya; mungkin sebuah jubah ungu tua yang sudah dibuang oleh seorang petugas, intinya adalah jubah yang berwarna keungu-unguan, warna kerajaan." ${ }^{5}$ Bagaimanapun itu, jelasnya nampak perlakuan tersebut hanya bertujuan untuk mengolok-olok dan menghina Yesus. Gerard Sloyan juga mengatakan dalam bukunya "diragukan bahwa yang dikenakan jubah ungu seperti biasa pakaian istana, lebih mungkin berwarna merah tua, sobekan kain yang kebetulan ada di tangsi.",

Jubah ungu memang merupakan pakaian Raja yang mahal dan merupakan pakaian khusus untuk Raja dan para bangsawan saja, tidak semua orang dapat memiliki jubah ungu tersebut. Dalam Kamus Alkitab yang ditulis oleh W.R.F. Browning "Bahan yang digunakan untuk membuat warna ungu tersebut merupakan cairan dari binatang laut yang didapatkan di pantai laut Palestina. ${ }^{7}$ Luis M. Bermezo juga mengatakan bahwa warna ungu tersebut dihasilkan dari binatang laut dan sangat mahal. ${ }^{8}$ Karena kain ungu ini sangat mahal dan juga peruntukkannya, kemungkinan tidak dimiliki oleh prajurit-prajurit.

Sedangkan menurut Stefan Leks dalam bukunya, "Mula-mula pada tubuh telanjang Yesus, dikenakan jubah ungu, pakaian kebesaran Raja Yunani. ${ }^{9}$ Menurutnya, jubah ungu yang dikenakan pada Yesus merupakan jubah kebesaran seorang Raja yang mahal. Menjadi suatu persoalan mengenai jubah ungu ini, apakah jubah yang dikenakan pada Yesus itu merupakan kain ungu biasa atau merah tua yang dimiliki oleh prajuritprajurit atau merupakan jubah kebesaran yang dipakai oleh Raja. Ini merupakan suatu persoalan yang perlu dijelaskan dan tentunya berdasarkan apa yang teks Alkitab katakan dan penafsiran-penafsiran yang mendukung. Dari latar belakang masalah tersebut, Maka penulis berkeinginan untuk menulis tentang bentuk penghinaan yang dilakukan terhadap Yesus berdasarkan Markus 15:16-20, maka dari itu judul yang diangkat oleh penulis adalah: KAJIAN BIBLIKA TENTANG PENGHINAAN TERHADAP YESUS BERDASARKAN MARKUS 15:16-20 DAN IMPLIKASINYA BAGI ORANG PERCAYA MASA KINI.

\section{Pokok Masalah}

Dengan melihat latar belakang masalah di atas, maka yang menjadi pokok masalah dalam skripsi ini adalah :

Pertama, Apa bentuk penghinaan yang dilakukan terhadap Yesus berdasarkan Markus 15:16-20?

Kedua, Apa implikasi yang dapat diambil dari penghinaan yang dilakukan terhadap Yesus berdasarkan Markus 15:16-20?

\footnotetext{
${ }^{5}$ Leon Morris, Tafsiran Injil Matius (Surabaya: Momentum, 2016), 725.

${ }^{6}$ Hadiwiyata Hendrowarsito, Tafsiran Injil Markus (Yogyakarta: Kanisius, 1982), 141. (Gerard S. Sloyan)

${ }^{7}$ W.R.F. Browning, Kamus Alkitab (Jakarta: BPK Gunung Mulia, 2008), 470.

${ }^{8}$ Luis M. Bermezo, Selubung Kirmizi; Jejak-jejak Penyaliban Almasih (Yogyakarta: Kanisius, 2008), 221

${ }^{9}$ Stefan Leks, Tafsiran Injil Markus (Yogyakarta: Kanisius, 2003), 479.
} 


\section{Tujuan Penelitian}

yaitu:

Dalam penulisan skripsi ini ada dua tujuan yang hendak dicapai oleh penulis,

Pertama, menjelaskan bentuk penghinaan yang dilakukan terhadap Yesus.

Kedua, memberikan implikasi dari penghinaan yang dilakukan terhadap Yesus berdasarkan Markus 15:16-20.

\section{Manfaat penelitian}

Manfaat penulisan skripsi ini adalah :

Pertama, Skripsi ini dapat bermanfaat bagi pembaca untuk menambah pengetahuan

Kedua, orang percaya dapat mengetahui tentang bentuk penghinaan yang dilakukan terhadap Yesus secara mendalam.

Ketiga, untuk memenuhi persyaratan akademik dalam mencapai gelar sarjana (S1) di Sekolah Tinggi Filsafat Jaffray Makassar.

\section{Metode Penelitian}

Dalam penulisan skripsi ini, penulis menggunakan metode penulisan kualitatif dengan menggunakan prinsip-prinsip hermeneutik, eksegesis dan penafsiran untuk menjelaskan Markus 15:16-20. ${ }^{10}$ Dalam bab II (introduksi) menggunakan teknik pengumpulan data melalui pencarian sumber atau kepustakaan, antara lain menggunakan Alkitab, kamus, tafsiran, literatur, dan buku-buku yang berkaitan dengan pembahasan Markus 15:16-20. Dalam bab III juga mengunakan metode penafsiran hermeneutik. Arti dari hermeneutik adalah menyampaikan, menjelaskan, menerjemahkan. ${ }^{11}$ Dalam eksegesis Markus 15:16-20 penulis menjelaskan nas berdasarkan narasi dan menggunakan metode penafsiran eksposisi untuk menjelaskan bagian teks dari Markus 15:16-20 "Eksposisi diartikan sebagai penyusunan hasil eksegesis secara berurutan, kata per kata."12 Bab IV menggunakan metode implikasi, yaitu keterlibatan atau keadaan terlibat. ${ }^{13}$ Implikasi dalam penulisan ini adalah implikasi Teologis dan implikasi praktis tentang bagaimana sikap orang percaya untuk menghormati, menghargai dan tunduk kepada Yesus yang telah berkorban dan sebagai Raja atas kehidupan.

\section{Sistematika Penulisan}

Sistematika penulisan ini sebagai berikut:

Bab I, bagian ini terdiri dari pendahuluan yang meliputi: Latar Belakang masalah, pokok masalah, tujuan Penelitian, manfaat penelitian, metode penelitian, batasan penelitian dan sistematika penulisan.

Bab II, merupakan pembahasan latar belakang kitab Markus yang terdiri dari, penulis kitab Markus, garis besar kitab Markus, tujuann penulisan kitab Markus, tema kitab Markus, keunikan kitab Markus dan strukutur kitab Markus.

Bab III, merupakan eksegesis tentang penghinaan terhadap Yesus berdasarkan Markus 15:16-20 yang terdiri dari struktur nas, penjelasan nas Markus 15:16-20

\footnotetext{
${ }^{10}$ Chelsia dan Panggarra, 123; Sugiono, 87.

${ }^{11}$ Hasan Sutanto, Hermeneutik: Prinsip dan metode penafsiran Alkitab (Malang: Literatur SAAT, 2007), 1.

${ }^{12}$ Jerry Rumahlatu, Hermeneutika Sepanjang Masa (Jakarta: Cipta Varia Sarana, 2011), 114.

13،"Kamus Besar Bahasa Indonesia,"n.d.
} 
Bab IV, merupakan penjelasan implikasi tentang penghinaan terhadap Yesus berdasarkan Markus 15:16-20 bagi orang percaya masa kini.

Bab V, merupakan kesimpulan dan saran.

\section{Kesimpulan}

Setelah mengkaji tentang penghinaan yang dilakukan terhadap Yesus, sebelum Yesus dibawa ke Golgota untuk disalibkan, di mana persoalan yang melatarbelakangi penulisan skripsi ini adalah tentang jubah ungu yang dikenakan pada Yesus. Penulis mengambil kesimpulan sebagai berikut: Pertama, jubah ungu yang dikenakan kepada Yesus bukanlah jubah yang dipakai oleh seorang Raja, sebuah jubah yang mahal, yang melambangkan kerajaan. Sebab tidak mungkin jubah ungu mahal tersebut dan bahkan yang menggunakannya hanya orang-orang tertentu (Kaisar atau Raja atau para bangsawan) dikenakan pada tubuh Yesus, yang siap dianiaya.

Kedua, bahwa jubah yang dikenakan pada Yesus merupakan pakaian atau kain ungu biasa dan mungkin lebih tepatnya kain merah tua yang pada saat itu merupakan pakaian yang dipakai oleh prajurit-prajurit Romawi. Kemungkinan kain yang sudah usang dan tidak dipakai lagi, yang terdapat di gedung pengadilan, tempat di mana Yesus diperlakukan semena-mena oleh serdadu-serdadu tersebut. Oleh karena prajurit-prajurit yang memiliki pakai tersebut, maka tidak sulit bagi prajurit-prajurit tersebut menemukan sebuah kain yang akan digunakan untuk mengolok-olok Yesus.

\section{Saran-saran}

Berdasarkan Kajian Biblika tentang Penghinaan Yang Dilakukan Terhadap Yesus berdasarkan Markus 15:16-20 maka penulis ingin memberi saran:

Pertama, bagi para pemimpin Gereja, haruslah menggali tentang kebenarankebenaran yang terkandung dalam penderitaan Yesus, agar diajarkan kepada jemaat yang digembalakan. Sebab inti dari Injil adalah penderitaan Yesus. agar jemaat mengetahui secara mendalam tentang penderitaan Yesus dan dapat merefleksikannya dalam kehidupan sehari-hari.

Kedua, bagi orang-orang percaya, haruslah benar-benar merenungkan tentang apa yang telah Tuhan Yesus lakukan demi manusia yang dikasihi-Nya. Tuhan Yesus menderita penderitaan badani dan juga menerima cercaan dan perlakuan yang sangat keji dari orang-orang yang menyiksa-Nya. Tentang ini, setiap orang percaya harus merenungkannya dan merefleksikannya dalam kehidupan.

\section{Kepustakaan}

Howard Klark Kee.Dkk. Alkitab Edisi Studi. Jakarta: Lembaga Alkitab Indonesia, 2010. Barclay, William. Pemahaman Alkitan Setiap Hari. Jakarta: Gunung Mulia, 2008.

Barclay, William. Pash, Yakobus Psl: 1 \& 2 Petrus. Jakarta: BPK GunungMulia, n.d. Beavis, Marry Ann. Commantaries on The New Testament. United States of America: Baker Academic, 2011.

Bergant, Dianne dan Robert J. Karris. Tafsiran Alkitab Perjanjian Baru. Yogyakarta: Kanisius, 2002.

Bermezo, Luis M. Selubung Kirmizi; Jejak-jejak Penyaliban Almasih. Yogyakarta: Kanisius, 2008. 
Bolkestin, Marinus Hendrik. Kerajaan Yang Terselubung. Jakarta: BPK Gunung Mulia, 2004.

Bratcher, Robert G. dan Eugene A. Nida.Pedoman Penafsir Alkitab Injil Markus. Jakarta: Lembaga Alkitab Indonesia, 2014.

Browning, W.R.F. Kamus Alkitab.Jakarta: BPK Gunung Mulia, 2008.

Bruggen, Jakob van. Markus: InjilMenurutPetrus.Jakarta: BPK Gunung Mulia, 2006.

Carson, D. A. and Douglas J. Moo. An Introduction to the New Testament.United States America: Zondervan Academic, 2009.

Chelsia, Anizah dan Robi Panggarra. "Iman Perempuan Kanaan Berdasarkan Kitab Matius 15:21-28.” Jurnal Ilmu Teologi dan Pendidikan Agama Kristen 1, no. 2 (Desember 2020): 123-143. https://ojs.sttjaffray.ac.id/jitpk/article/view/511/pdf_8.

Drane, John. Memahami PerjanjianBaru. Jakarta: BPK GunungMulia, 2016.

Duyverman. Pembimbing ke Dalam Perjanjian Baru. Jakarta: BPK Gunung Mulia, 1966.

Flavius, Aldorio. "Makna Tujuh Ungkapan Yesus Disalib Bagi Orang Percaya” Jurnal Jaffray. Vol.13 no.2 (Oktober, 2005).

Guthrie.dkk. Tafsiran Alkitab Masa Kini. Jakarta: BPK Gunung Mulia, 1983.

Guthrie, Donald. Pengantar PerjanjianBaru. Surabaya: Momentum, 2010.

Halley, Henry. Penuntun Ke Dalam Perjanjian Baru. Surabaya: YAKIN, 1979.

Hayes, John. Pedoman Penafsiran Alkitab. Jakarta: BPK Gunung Mulia, 2006.

Hendrowarsito, Hadiwiyata. Injil Markus. Yogyakarta: Kanisius, 1982.

Henry, Mathew. Tafsiran Injil Markus.Surabaya: Momentum, 2011.

Kaiser, Walter. Toward An Exegetical Theology. Gran Rapids: Baker Book House, 1981.

Kuncahyono, Trias. Imperium Romanum, Kota Para Nabi dan Tragedi di Tanah Suci. Jakarta: Kompas, 2011.

Lane, William.The New International Commentary on The New Testamant, The Gospel Of Mark. United States of America: Eerdmans Publishing Company, 1974.

Lee, Jaerock. Pesan Salib; The Message of the Cross. Seoul: Urim Books, 2002.

Leks, Stefan. Tafsir Injil Markus. Kanisius, 2003

Ludji, Barnabas. Kerajaan Mesias. Jakarta: Sekolah Tinggi Teologi Jakarta, 1999.

Marclaren, Alexander. The God Who Serves. United States of American: The Fleming H. Revell Company, 1987.

Pfeiffer, Charles F. dan Everett F. Harrison, ed. The Wycliffe Bible Commentary. Malang: Gandum Mas, 2001.

Phillips, John. The Gospel Of Mark. United States of America: Kregel Publications, 2004.

Reidel. Tafsiran Injil Markus. Jakarta: BPK Gunung Mulia, 1956.

Reiling, J. Pedoman Penafsiran Alkitab: Injil Lukas. Jakarta: Lembaga Alkitab Indonesia, 2005.

Reynold, Rendy Agustin. Makna Frasa Roh Membawa Yesus untuk Dicobai Iblis Dalam Matius 4:1-11 Dan Implikasinya Bagi Orang Percaya. Makassar: Sekolah Tinggi Teologia Jaffray Makassar, 2016. (Grant R. Osborne)

Sloyan, Gerald. Injil Markus. Yogyakarta: Kanisius, 1982.

Solihin, Benny. 7 Langkah Menyusun Khotbah yang Mengubah Kehidupan. Malang: Literatur SAAT, 2010.

Stamps, Donald C. Alkitab Penuntun Hidup Berkelimpahan. Malang: Gandum Mas, 2010. 
Stuart, Douglas. Eksegese Perjanjian Lama. Malang: Gandum Mas, 1994.

Sugiono. "Pendekatan Penginjilan Kontekstual Paulus Berdasarkan Kisah Para asul

17:16-34.” Jurnal Ilmu Teologi dan Pendidikan Agama Kristen 1, no. 2

(Desember 2020): 87-102.

https://ojs.sttjaffray.ac.id/jitpk/article/view/492/pdf_6.

Sutanto, Hasan. Perjanjian Baru Interlinear Yunani-Indonesia dan Konkordansi Perjanjian Baru Jilid I. Jakarta: Lembaga Alkitab Indonesia, 2003.

Tenney, Merrill. Survei Perjanjian Baru. Malang: Gandum Mas, 2017.

Veldhuis, Hendry. Aku Tahu Yang Kupercaya. Jakarta: BPK Gunung Mulia, 2010.

Zuck, Roy B. Basic Bible Interpretation: A Practical Guide to Discovering Biblical Truth. Colorado: Cook Comunication Ministries, 1991. 